\title{
Application of advanced insulating materials in historical buildings
}

\author{
Camilla Saio $^{1}$, Kevin Nocentini ${ }^{2}$, Luca A.Tagliafico ${ }^{1}$, Pascal H. Biwole ${ }^{2,3 *}$, \\ Patrick Achard ${ }^{2}$
}

${ }^{1}$ DIME-Dipartimento di Ingegneria Meccanica, Energetica, gestionale e dei trasporti

Università degli Studi di Genova, Via all' Opera Pia 15/a, Genoa 16145, Italy

${ }^{2}$ MINES ParisTech, PSL research university, PERSEE, Centre Procédés, Energies Renouvelables et Systèmes Energétiques, 1 Rue Claude Daunesse, CS 10207, F-06904, Sophia Antipolis Cedex, France

${ }^{3}$ University Clermont Auvergne, CNRS, SIGMA Clermont, Institut Pascal, F-630000 ClermontFerrand, France

Email: pascal.biwole@uca.fr

\begin{abstract}
Energy saving interventions for historical buildings require an accurate study on measures to be adopted and on the modalities of their application. This is in terms of energetic renovation with particular reference to historical, artistic and landscape profiles, considering that the substantial character and aesthetic aspects of the buildings are not to be changed. These types of buildings must be preserved and enhanced, beyond a binding adaptation to the regulation requirements. This study analyses the use of an innovative material, the silica aerogel, with the aim of achieving a high level of energy improvement. In many of the cases subject of numerical studies, buildings equipped with the aerogel-based thermal insulation show better hygro-thermal performance than when using other insulating materials. The objective of this study is to develop numerical models in Energy Plus, based on a targeted case study, to examine different exterior wall structures insulation and related energy behavior, considering defined assessment criteria such as heat losses, time lag, decrement factor, comfort index. The thickness dependency on annual heating set point, the heating and cooling load, and the operating costs are also investigated. The thermal performance of walls with aerogel-based insulation is compared with different insulating materials and configurations, applied on the historical building structure. Finally, a cost analysis for the different solutions, different climates, in retrofitting of historical buildings, is taken into consideration.
\end{abstract}

Keywords: Thermal Insulation, Silica Aerogel, Historical Buildings, Energy Savings.

\section{INTRODUCTION}

\subsection{Insulation for historical buildings}

The theme of energy efficiency for existing buildings is a topic of high priority and importance since new buildings represent every year only less than $5 \%$ of the built sector in most countries. It becomes very delicate in regards to historical buildings, which, given their nature, require carefully designed interventions that do not involve any substantial alteration to their character and appearance, especially in reference to their historical, artistic and landscape profile.

When intervention on such buildings is required, the scope of the work is within the restoration field and it is therefore necessary to follow the minimum intervention criteria, to maintain reversibility and compatibility for appropriate landscaping and architectural integration [1]. It is therefore necessary to find a good compromise between energy efficiency and conservation, with specific maintenance interventions to refurbish those buildings using un-invasive and reversible techniques.

In these instances, a study of the measures and modalities to be adopted, in terms of energy improvement, is necessary, with a particular focus on preserving all the historical beauty of the buildings.

The thickness of insulation layers becomes a major issue of concern especially in cities [7]. Moreover, in the case where an internal insulation is used, the choice of the type of insulation should lead to a minimal reduction of the volume of the rooms, in accordance with the rules to be applied for the specific intended uses and in compliance with the minimum accessibility, visitability and adaptability requirements for the architectural barriers removal [11].

In the study, it should also be considered that the historic buildings envelopes usually present humidity due to the 
capillarity. So, it is necessary to pay attention to the type of insulation used, limiting as much as possible or even removes several moisture problems of the interior thermal insulation systems.

\subsection{Typology of historical buildings}

Historical buildings tend to be built with thick walls. A significant example is represented by forts.

These architectures are characterized by the presence of steady seasonal temperatures, which guarantee comfortable conditions especially during the summer season.

The walls perform well their function and act as a boundary against the outdoor climate. In fact, the high thermal inertia mitigates the high summer temperatures, thus delaying the thermal flux entry, resulting from strong solar radiation.

Meanwhile in winter, they insulate from the cold air and they retain the heat supplied, functioning as thermal storage.

The fortifications in Europe are designed through the ballistic science, the mathematics and the technology, since many of them were built after the development of firearms and especially of cannons in the 15th century, setting the stage for the end of the cavalry and therefore they require more sophisticated defensive techniques.

In order to reduce the devastating impact of the cannon ball, an oblique form was used for outer walls, while in regards to range, the position of the guns was designed to cover the surrounding area, which should be as free as possible.

These constructions are built using a wide variety of workforce, drawn depending on guns and often recall a star shape.

Significant examples are the works carried out during the fourteenth and fifteenth centuries by Francesco di Giorgio, Antonio da Sangallo, Filippo Brunelleschi, Michelangelo Buonarroti.

Other relevant examples are the eighteenth-century military construction in France (the most important European country at the time). The fortifications were built at the borders and their geometric shape presides over all the sites of the city.

A particularly important role is played by the conceptual models and experience in fortifications of the French Colonel Le Prestre Sebastien de Vauban, which becomes official secretary of all the French fortifications. Such examples present typical elements in building protection, such as ravelins, horns, tongs, etc.

Two Forts are taken as examples, which, despite being from different eras, present analogies and common elements: The Fort Carré in France and the Fort Begato in Italy.

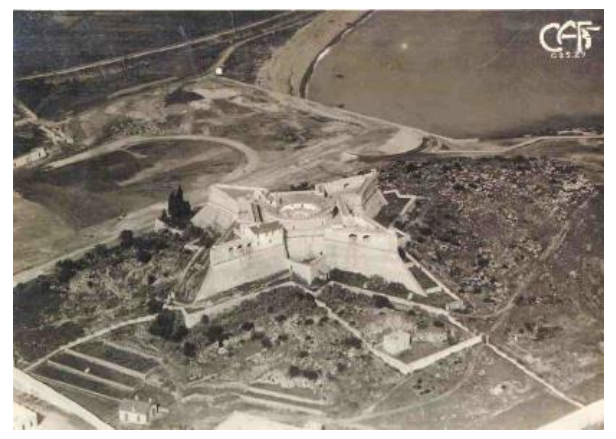

Figure 1. Aerial photo of the Fort Carré - (France, 1920) [2]
These forts have many areas with self-supporting shadow, due to the articulated geometry of the building volume.

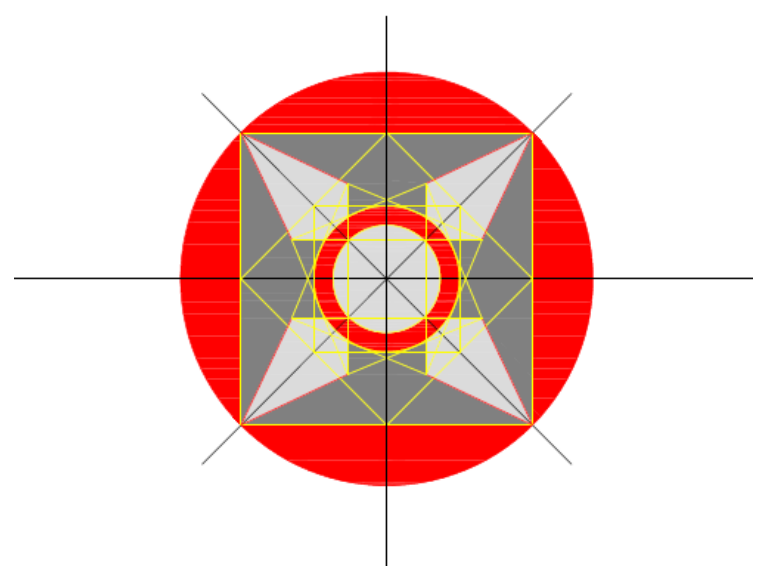

Figure 2. Fort Carré geometry

The Fort Carré has different geometric traces, consisting of circles, octagons and squares. From the outer circle of the tower, a circumscribed octagon determines the insertion points of the ramparts, inscribed in a square.

For the construction of the fort different types of limestone have been used, as their properties were suitable to different sites. A soft limestone was used for the blocks that constitute the plans, while the rest of the construction is a limestone amalgam coupled with a mortar composed of water and sand.

Also, bricks are present, mainly placed in correspondence of the frames on the openings, in some floors and stairways.

In this study, Fort Begato is also presented, a significant example of military construction located in Genoa, equipped with angular ramparts and a central court, and it is used as a model for a thermal energy system simulation.

It is a nineteenth-century military building with a square plan three floors plus one mezzanine, with an inner courtyard with four corner bastions, of which one is currently in ruined state. Its volume is pure, essential and its proportions are simple. On the four fronts stand out large gunner openings, alternating with thin slits for riflemen.

The perfectly squared architectural elements are made out of stone block masonry from Finale.

The building walls thickness is variable, in particular, it increases in proximity of the ramparts to the fortification corners. The roof is built with a wooden structure and slabs of slate cladding.

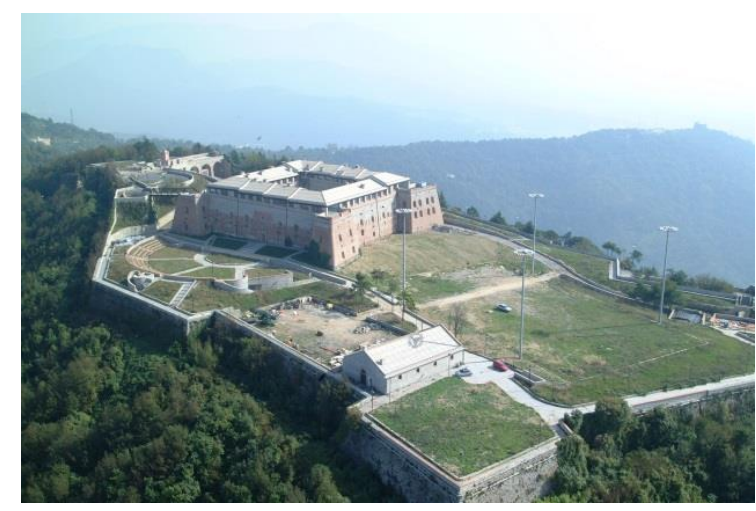

Figure 3. Aerial view of Fort Begato (Genoa, Italy) courtesy of the municipality of Genoa 
Buildings in historic centers also present critical factors. They have a very high shade factor, being very close to each other. Moreover, during summer, they are subject to heatisland effect in urban areas.

\subsection{Thermal insulation}

Thermal insulation is a material that retards the rate of heat flow by conduction, convection and radiation. It reduces the thermal transmittance ( $U$ value) and therefore the heat loss through the wall [10].

There are different kinds of insulation and many classifications of thermal insulating materials.

A classification based on the origin of the raw material which composes the largest percentage of the material divides them into five categories: vegetal, fossil, mineral, animal or recycled.

The insulation materials can also be ordered by their macrostructure type: Fibrous, compact or grainy [3].

Recent developments allowed the spreading of new insulating materials, such as phase-change materials and multi-layer heat reflective insulation.

The PCM (Phase Change Material), pass from the solid to the liquid phase, accumulating and releasing heat energy. So, they contribute in regulating heat exchanges through the envelope components.

In the next section, the innovative material aerogel is described and the qualities of this material regarding the insulation of historic buildings are explained.

\section{SILICA AEROGEL APPLICATIONS}

Traditionally used in the aerospace industry, silica aerogel is a material with many particular properties, among which the most important consists in its insulating effect, presenting a great advantage: a high performance/thickness ratio.

In this study two different types of silica aerogel based materials are considered, one for the internal insulation of the masonry, the second for the outer insulation.

For most cases studied, the aerogel based insulating material shows better performance than other insulating materials.

Silica aerogels are highly porous thermal insulating materials made of amorphous silica nanoparticles [4]. However, pure silica aerogels are fragile, with low mechanical module, which prevents a proper use in the building sector. Making aerogel composite materials by combining fibers with a pre-gel mixture of a gel precursor or by impregnating a fiber network by such a mixture seems to be a promising way to enhance the mechanical properties of such materials. After drying, the resulting composite is called aerogel blanket. The aerogel blanket is mechanically strengthened, flexible and has a thermal conductivity as low as $0.015 \mathrm{~W} \cdot \mathrm{m}^{-1} . \mathrm{K}^{-1}$ (that is lower than air!)

Aerogel blankets are so called super-insulating materials and are one of the new high performances thermal insulating materials for building applications. Their thermal performances are two to five times better than conventional insulating materials (e.g. organic wool, polymer foams ...) but they are not competitive yet in the building insulation market. The use of super-insulating materials is nevertheless useful for very specific insulation needs or in areas where it can offer a cost advantage due to a space saving effect.
Typical examples include thermal bridges treatment, side-on balcony and roof balcony construction, interior insulation in urban area where the living space is scarce and expensive or retrofitting of historical building in which outside facade cannot be affected.

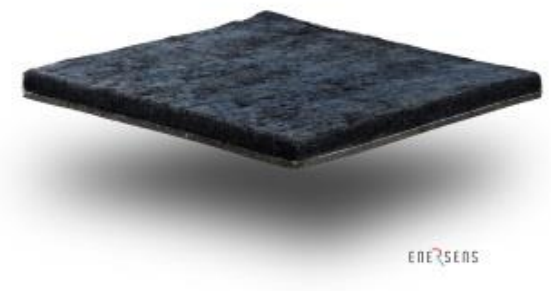

Figure 4. Silica aerogel

Mixing aerogel granules with mortar is another way to use aerogel as a thermal insulation system [5]. This light mortar can be applied to the external surface of a building to produce a thermally insulating coating. The coating is made of a mineral or organic hydraulic binder, insulating filler comprising silica aerogel granules, structuralizing filler and some additives. The aerogel granules replace somehow the sand used in conventional mortar. The mortar is prepared industrially as a dry composition by mixing all abovementioned components and then the mix is stored in bags and transported to the site for use. The coating has a thermal conductivity of $0.027 \mathrm{~W} \cdot \mathrm{m}^{-1} . \mathrm{K}^{-1}$ and a density of $200 \mathrm{~kg} \cdot \mathrm{m}^{-3}$ at ambient use conditions.

\section{OBJECTIVES OF THE ENERGY PLUS SIMULATIONS FOR HISTORICAL BUILDING}

The objective is to develop a numerical model with Energy Plus, for purposes of calculating the optimal thickness and conducting a cost analysis for different typical climates for historical buildings retrofitting.

The energy audit scope is the reduction of energy usage, through evaluation of energy usage profiles.

The energy audit of a historic building can present problems, like the deficit of appropriate plants or sections, of materials knowledge and of the stratigraphy of the interior and exterior walls.

Having access to that knowledge, through archival research regarding the original building and the changes occurred during the time, is needed for the adequate design of interventions [1].

Then a sensitivity analysis is carried out to determine the thickness dependency on annual heating load.

The objective is to examine the hygrothermal performance of walls and to compare different thermal insulation configurations

Two exterior wall structures are examined: no insulation and interior insulation. Among the assessment criteria, the most important factor presented is the amount of heat losses.

The energy behavior of building wall structure is the main point to investigate. The object here is to find the best wall structure and the number and position of insulation layers on the exterior wall for continuous heating operation mode of 
forts.

\section{METHODOLOGY ZONE HEATING AND INTENDED USE}

The energy needs of "Forte Begato", used as an example for this study, have been calculated with Energy Plus software.

Different thermal zones were taken into account, according to two different parameters: the orientation of the building and the intended use of the different areas.

Considering the high thickness of the walls of the fortress, the heating zones have been designed from the middle of the wall, so that the overall volume of the building does not increase, once assigned the thickness of the walls.

Instead, for the calculation of the heat flow dispersed through the windows, the effective glass window area is considered. In this case, it coincides with the glass window surface measured on the walkable surface of the internal perimeter of the building.

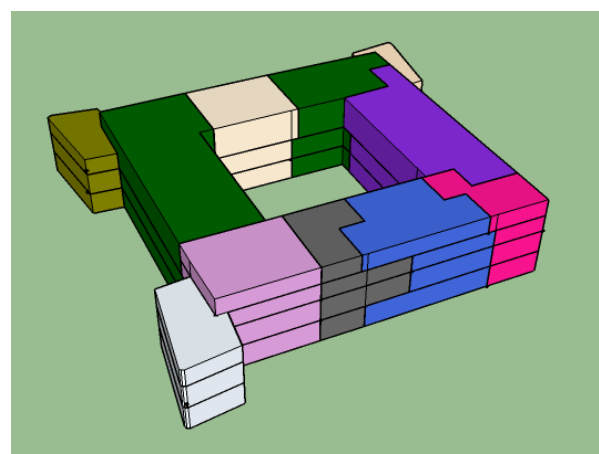

Figure 5. Thermal zones 3D model

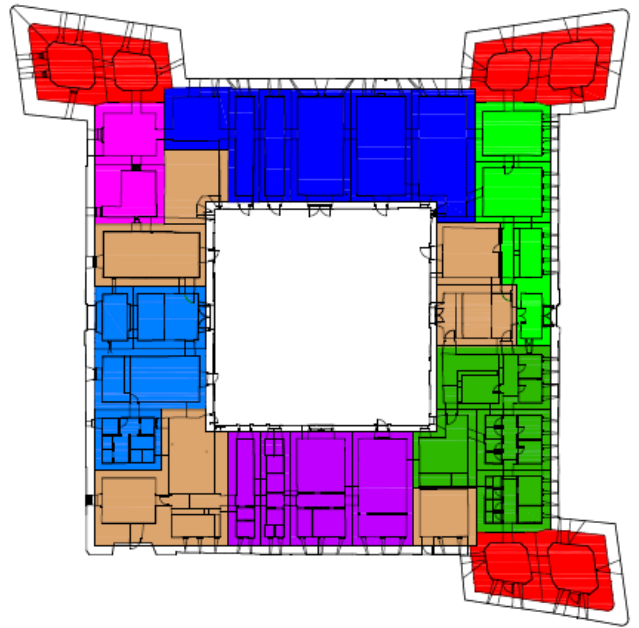

Figure 6. Thermal zones plant

Besides, as far as the horizontal structure is concerned, a simplified method, which considers all the layers as if they were all plane, has been considered. This method has been used both for the saddle roof and for the vaulted ceiling.

The total thermal resistance of a building component, containing an air cavity strongly ventilated, is obtained by omitting the thermal resistance of the interspace of air and of all the other layers that separate the above air cavity from the external environment and by including a superficial thermal resistance, corresponding to the surface of the building (i.e, equal to the internal superficial thermal resistance of the same component).

For the masonry and for the thermal insulation, the following data have been used:

Wall structure: limestone

ITI = interior thermal insulation: Blanket aerogel

ITE $=$ external thermal insulation: Aerogel mortar

Table 1. Wall structure properties

\begin{tabular}{ccccc}
\hline & $\begin{array}{c}\text { Thermal } \\
\text { conductivity } \\
(\mathrm{W} /(\mathrm{m} . \mathrm{K}))\end{array}$ & $\begin{array}{c}\text { Heat } \\
\text { capacity } \\
(\mathrm{J} /(\mathrm{K} . \mathrm{kg}))\end{array}$ & $\begin{array}{c}\text { Density } \\
\left(\mathrm{kg} / \mathrm{m}^{3}\right)\end{array}$ & $\begin{array}{c}\text { Thickness } \\
(\mathrm{cm})\end{array}$ \\
\hline Limestone & 2 & 840 & 2300 & 170 \\
\hline $\begin{array}{c}\text { Blanket } \\
\text { aérogel }\end{array}$ & 0.015 & 750 & 150 & 2 \\
\hline $\begin{array}{l}\text { Aérogel } \\
\text { mortar }^{2}\end{array}$ & 0.027 & 1100 & 200 & 4 \\
\hline
\end{tabular}

Subsequently, the insulation on the exterior walls has been inserted and a comparison between the different types of insulation has been made.

In this simulation, the building thermal bridges have not been taken into account, since generally the problem does not arise in historic masonry buildings, which are characterized by a historic fabric quite uniform. In these cases, the thermal bridges are generally limited to the windows.

Obviously, the problem arises in buildings affected by structural recovery made with modern materials and new technologies, that do not respect the original construction design of the building, heavily modifying the status of the building [1].

\section{RESULTS}

The trends of thermal energy requirements for heating and for cooling are shown on figures 7-8-9-10.

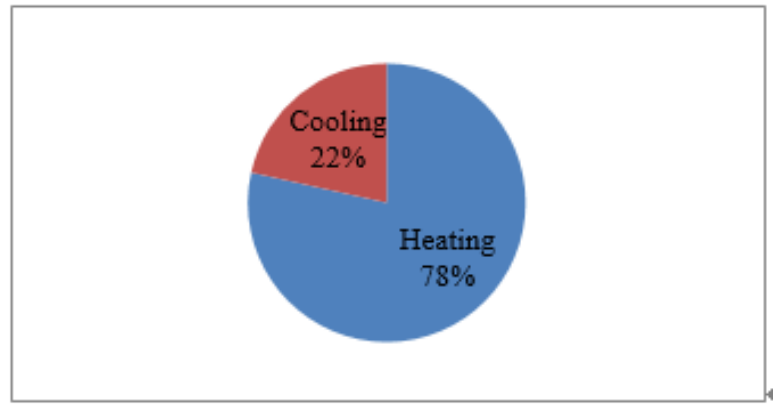

Figure 7. Heating and cooling annual overview end use

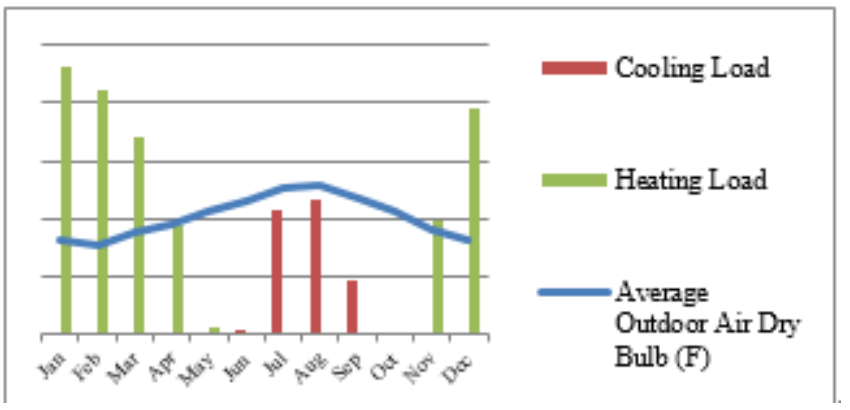

Figure 8. Heating and cooling monthly load profiles 
Comparison graphs with and without insulation are also presented on figures $9-10$

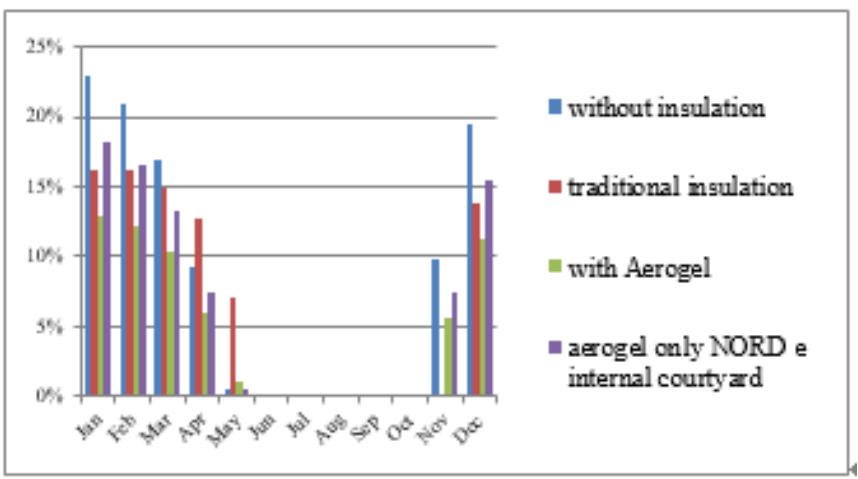

Figure 9. Monthly percentage trend of heating load depending on the insulation type used, compared to the total heating needs

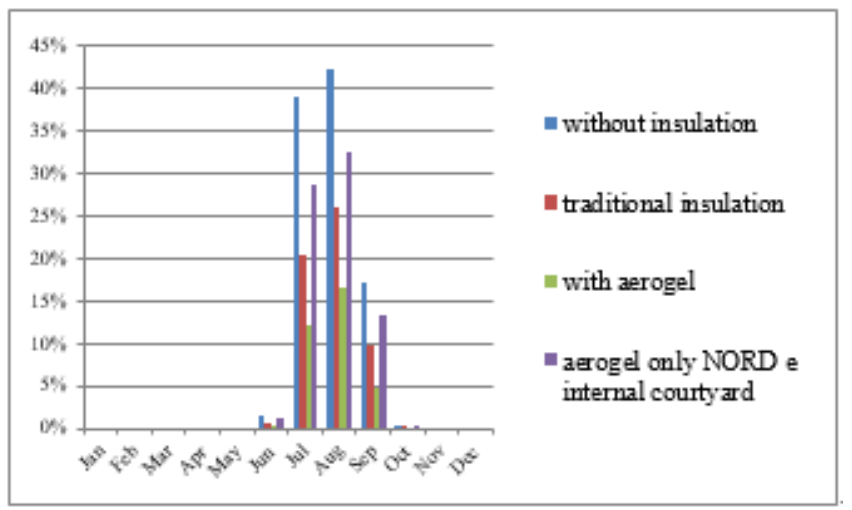

Figure 10. Monthly percentage trend of cooling load depending on the type of insulation used, compared to the total cooling needs

From the graph, result of the study carried out, we may note that, for instance, there is around a $25 \%$ reduction in heating demand using traditional insulation types, meanwhile, if the same amount of aerogel, in terms of thickness, is applied, we achieve about a $40 \%$ reduction.

Besides, during the summer season, it is possible to get a energy saving up to $40 \%$ via traditional insulation and an energy saving of up to $65 \%$ by employing aerogel.

This analysis takes into account only the insulation of exterior walls, not adding any modifications to the floors and the roof, the latter being recently renovated, is already equipped with an inner insulation.

Considering the high costs associated to aerogel, in many cases still experimental, a different solution is proposed: the application of this type of insulation only on the north and on the walls of the inner courtyard. This type of insulation can reduce considerably the heat losses of the entire building by $25 \%$ in summer and by $20 \%$ in winter, compared to the condition without insulation.

\subsection{Choice of the insulation depending on the intended use and the period of use}

The choice on insulation type may also be conceived based on the intended use and its employment period.

In fact, hotels, restaurants, offices, museums, etc. do have very variable usage profiles.
For such reason, a comparison between the different potential uses and an heat transfer analysis of the wall was conducted, taking into account the variations of the building's energy needs.

It is also carried out a study on the energy profiles of different uses.

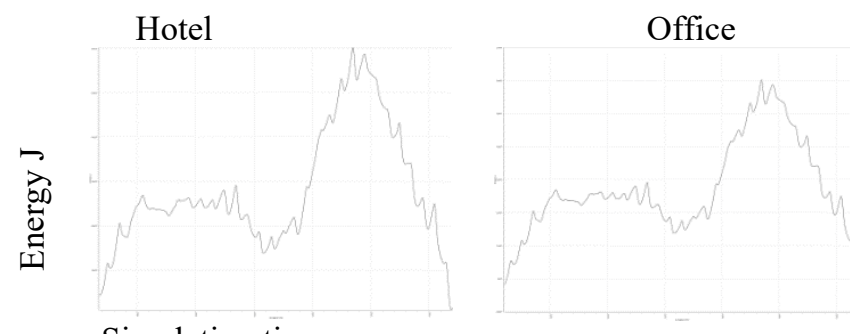

Simulation time

Figure 11. Monthly district heating for different end use profiles in January

Daily energy peaks, as showed in the figure 11, depend on the period of use of the building.

In these case studies for different periods of use and for intermittently heated spaces, a better result is achieved by applying the insulation on the internal side.

\subsection{Influence of thickness on the amount of heat lost through the walls}

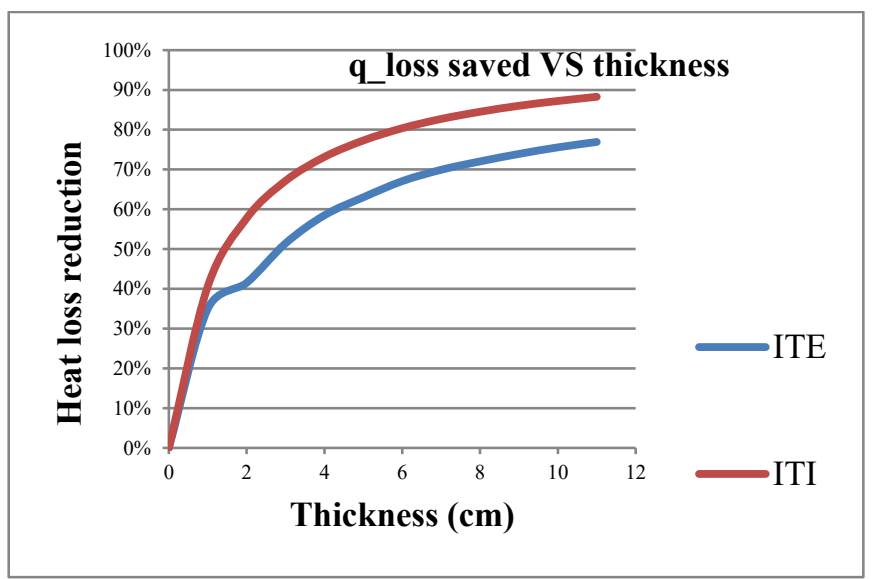

Figure 12. Heat loos reduction in function of the aerogel thickness

A criterion that could be useful is the heat losses through the walls (in this case, infiltration, ventilation of thermal bridges, etc., which accounts for about $45 \%$ of heating consumption is not taken into account). In the simulation, a constant internal temperature of $23^{\circ} \mathrm{C}$ is considered.

Figure 12 shows that the influence of thickness on the amount of heat lost through the walls is not linear. The main savings are obtained thanks to the first centimeters of insulation.

On the other hand, the price of insulation (manufacturing + installation) and often linear depending on the thickness. There is therefore an optimum thickness which minimizes the overall cost (material and energy).

In addition, as shown in the following graph (Fig.13), the aerogel has a different behavior depending on the type of masonry on which it is applied. As it could be noted, if the aerogel is applied on the stone, as in the case study, this lead 
to a greater increase of the reduction of the thermal losses, compared using other materials.

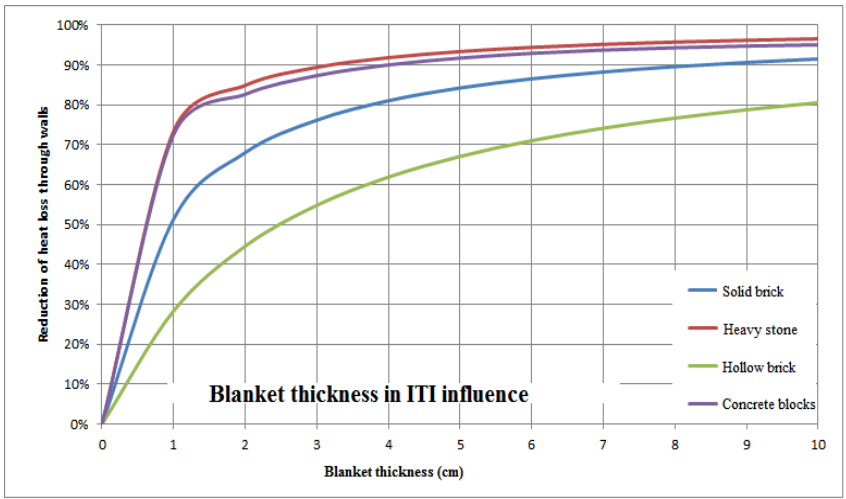

Figure 13. Blanket thickness in ITI influence study

\subsection{Time lag and decrement factor}

A surface-to-air temperature is imposed on the outer surface of the wall.

$T_{\text {sur,air }}=\frac{t_{\max }-t_{\min }}{2} * \sin \left(\frac{2 \pi \tau}{p}-\frac{\pi}{2}\right)+\frac{t_{\max }-t_{\min }}{2}+t_{\text {min }}$

The surface air temperature is an equivalent temperature of the outdoor surface temperature which, in the absence of solar radiation, would give the same heat flow through the wall as that caused by the combination of the actual surface temperature and solar radiation.

The decrement factor and the time lag are calculated in "free floating conditions" = no internal temperature imposed. In the considered range temperature $\left(-40,+50^{\circ} \mathrm{C}\right)$, the decrement factor and time lag are independent to the climatic conditions. (The thermal properties of the materials are considered constant)

The global exchange coefficients used are those of the French thermal regulation for buildings. The internal and external convection coefficients are respectively

$h_{i n}=7.7, h_{\text {ext }}=25$

Considering the thickness of the wall (1.7-2.3m), the time lag, it is obviously enormous (high thickness + high density) and the decrement factor is very low.

According to a study, considering the addition of ITI (Thermal insulation from inside: Blanket aerogel ${ }^{1}$ ) or ITE (Thermal insulation from the exterior: Mortar Aerogel ${ }^{2}$ ) insulation, the decrement factor becomes even smaller. On one hand, the temperature variations of the inside surface are too small, on the other hand, the calculation error of the software becomes more important than the temperature variations involved. This is particularly true since the wall under study is thick and / or heavy.

Having a decrement factor as low without insulation means that adding ITI or ITE will not impact comfort inside the building.

It is a material that has low density, and very low thermal capacity. As a result, it doesn't affect much the time lag, or the decrement factor of the masonry.
$\mathrm{C}=\mathrm{c}^{*} \rho$

However, it presents very high values in regard to thermal losses, thanks to its low thermal conductivity value.

\subsection{Choice of the insulation depending on the climate}

Previous studies on the optimal thickness show that the optimum rendering thickness is in the range of 1,7-4,4 cm and the payback period is in the range of 1,4-2,7 years depending on the climate. The thickness is optimized on a cost analysis for different climates for the case of retrofitting an old building.

The optimum thickness increases with the increasing heating set-point; however, it decreases with the increasing rendering cost. [7].

A study on the economic analysis referred to Nice is presented below, since the climate is similar to Genoa, the site where Fort Begato, the object of the study, is located.

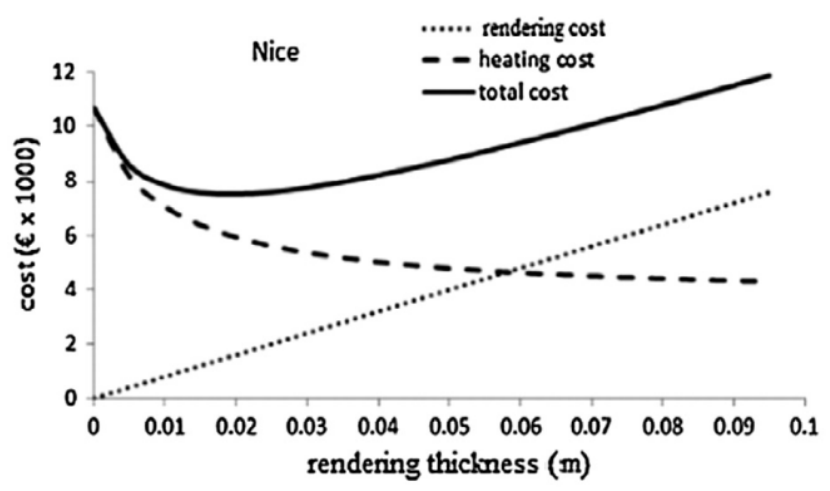

Figure 14. The heating consumption cost, the aerogel rendering cost, and the total cost for the climate of Nice

\section{HISTORICAL BUILDINGS INSULATION RECOMMENDATIONS}

Each historical building has different issues that need to be analyzed case by case (Annoni 1946) [9].

It follows that the measures and the modalities for the historic building energy improvement must be studied analogously to this principle.

However, some directions as how to intervene for the insulation of these buildings were given through some case studies on existing examples.

It is necessary to preserve the details of historic buildings both inside and outside.

In fact, many historic buildings present decorative elements with high artistic value, in facades and interiors, such as semi pillars, ashlars, architraves, friezes, cornices, complex and detailed moldings.

Any kind of intervention should be limited as much as possible, respecting the thickness of multiple geometric and decorative motifs.

\subsection{Aerogel application on historical buildings}

Silica aerogel used as thermal insulation material can reach a high level of energy improvement without compromising the construction details, details that could be lost under the traditional insulation. 
The characteristics that make the silica aerogel an insulating material suitable for the historic buildings retrofit are presented below.

- The versatility of these materials allows for both internal and external use, with the possibility to apply the aerogel on different substrates, constructions and compositions.

- The workability is very similar to the traditional ones, as they can be used on non-aligned, out of square, or even a curved support.

- Silica aerogel is flexible and can be used for any architectural and design solution.

- The reduced thickness of the material allows to maintain almost unaltered the interior spaces dimensions.

- The silica aerogel based material can be used for new buildings and for retrofitting existing ones since they have a high insulation performance and their application is easy, compatible with the traditional masonry facades, and using the well-known ordinary techniques [8].

Some practical and technical examples, that can be used as a benchmark for the renovation of historic buildings, are shown below.

In the case of military fortifications for example, we have chosen to intervene with the thermal insulation of the interior walls, in order to avoid impacting the outer landscape.

In case of an external insulation, thermal bridges caused by necessary structural renovation are prevented.

The insulation of shadow areas is useful to limit the heating cost, while it limits a little cooling cost.

Silica aerogel mortar is very suitable because it is characterized by a high water vapour resistance factor ( $\mu$ value) and a high liquid transport coefficient (A value). For this reason, the application of this technology on existing walls is suitable for envelopes that present humidity due to the capillarity, a common problem in historic buildings [8].

Instead, it must be considered that the interior thermal insulation can cause several moisture problems: inability to dry out over the years, condensation risk, etc., it is therefore necessary, use also the vapor barrier in the installation.

In particular for intermittently heated spaces, a better result is achieved by applying the insulation on the internal side.

Also, when using the thermal control index for the no heating operation mode, the best performance is achieved when placing the insulation at the interior wall surface [5].

On a case by case basis, in order to achieve a high level of comfort, also paints with thermal reflective properties can be employed.

But it should be also taken into consideration the thermal level comfort, depending on the insulation type involved.

An insulation with low wall U-values also has high wall surface temperatures and a reduced temperature at the wall/insulation interface [10].

Regarding the cost analysis, the aerogel costs are more expensive than the cost of traditional insulation.

The cost issue, in regards to the use of aerogel in the context of historic buildings, can be weighted on the basis of the value of building itself (which greatly increases with a requalification intervention), on the gains resulting from the type of activity of the intended use, on the duration of the building's life.

\section{CONCLUSIONS}

Among the major results, the possibility of using an innovative material based on silica aerogel is obtained, with a significant increase in performance, without compromising building details.

Among the results of the simulations, it is interesting to note that the demand for cooling is much lower than that for heating. In fact, the massive buildings, thanks to the high thermal inertia present comfortable conditions especially during the summer season.

In particular, the study shows that there is a reduction on heating demand about $40 \%$ using the aerogel and a $25 \%$ reduction using a traditional insulation type.

The application of aerogel only in shaded areas reduce the heat loss about $25 \%$ in summer and by $20 \%$ in winter, compared to the condition without insulation.

The choice of the insulation depends on the climate, for example for the climate of Nice the optimum rendering silica aerogel thickness is in the range of $1,7,4,4 \mathrm{~cm}$.

The characteristics of the silica aerogel make it suitable for historic buildings, for its properties of versatility, workability, flexibility and reduced thickness

Significant is also the choice to use silica aerogels based materials, as easy application material, compatible with traditional techniques.

Considering all factors for historical buildings retrofitting, it was found that insulation positioning mainly depends on formal visual aspects, but also depends on destination and period of use of the analyzed buildings.

For intermittently heated spaces, and also for the no heating operation mode, placing the insulation material as one layer at the interior wall surface is the most efficient from an energy consumption perspective and for the thermal control index objective.

\section{REFERENCES}

[1] De Santoli L., Bellia L., Corgnati S.P., D’Ambrosio A.F.R., Filippi M., Mazzarella L., Romagnoni P.C., Sciurpi F. (2014). Efficienza energetica negli edifici storici, Guida AICARR, Milano, Italia.

[2] Archives municipales d'Antibes, Grandeur et servitudes d'une place forte XVIeme-XIXeme siècles, Antibes, France, 1995, pp. 49-53.

[3] Benedetti C. (2012). Materiali isolanti, in Guide pratiche del Master CasaClima, Bu Press, Bolzano, Italia, pp. 10-15.

[4] Pierre A.C., Rigacci A. (2011). $\mathrm{SiO}_{2}$ Aerogels, in Aerogels Handbook, Springer: Adv. Sol-Gel Deriv. Materials Technol., pp. 21-45.

[5] Ibrahim M., Biwole P.H., Wurtz E., Achard et P. (2014). A study on the thermal performance of exterior walls covered with a recently patented silicaaerogel-based insulating coating, Build. Environment, Vol. 81, pp. 112-122. DOI: 10.1016/j.buildenv.2014.06.017

[6] Asan H., Sancaktar Y.S. (1998). Effects of wall's thermophysical properties on time lag and decrement factor, Energy and Buildings, Vol. 28, No. 2, pp. 159166. DOI: $10.1016 / \mathrm{S} 0378-7788(98) 00007-3$

[7] Ibrahim M., Biwole P.H., Achard P., Wurtz E., Guillame A. (2015). Building envelope with a new 
aerogel-based insulating rendering: Experimental and numerical study, cost analysis and thickness optimization, Applied Energy, Vol. 159, pp. 490-501. DOI: $10.1016 /$ j.apenergy.2015.08.090

[8] Ibrahim M., Wurtz E., Biwole P.H., Achard P., Sallee H. (2014). Hygrothermal performance of exterior walls covered with aerogel-based insulating rendering, Energy and Buildings, Vol. 84, pp. 241-251. DOI: 10.1016/j.enbuild.2014.07.039

[9] Bianco L., Serra V., Fantucci S., Dutto M., Massolino M. (2014). Thermal insulating plaster as a solution to refurbish historic building envelope: First experimental results, Energy and Buildings, Vol. 95, pp. 86-91. DOI: 10.1016/j.enbuild.2014.11.016

[10] Walker R., Pavía S. (2015). Thermal performance of a selection of insulation materials suitable for historic buildings, Building and Environment, Vol. 94, pp. 155-165. DOI: $10.1016 /$ j.buildenv.2015.07.033

[11] Ministero dei Lavori Pubblici, Decreto Ministeriale 14 giugno 1989, n. 236, Italy, G.U., 1989.

\section{NOMENCLATURE}

C

$\mathrm{h}$

$\mathrm{k}$

$\mathrm{t}$

$\mathrm{p}$

ITI

ITE

heat capacity, $\mathrm{J} / \mathrm{K}$

specific heat, $\mathrm{J} / \mathrm{kgK}$

convection coefficient, $\mathrm{W} \cdot \mathrm{m}^{-2} \cdot \mathrm{K}^{-1}$

thermal conductivity, W. $\mathrm{m}^{-1} \cdot \mathrm{K}^{-1}$

temperature $\mathrm{K}$

period, $\mathrm{s}$

interior thermal insulation: Blanket aerogel

external thermal insulation: Aerogel mortar

\section{Greek symbols}

$\rho$

density, $\mathrm{kg} / \mathrm{m}^{3}$

$\tau$

time, $\mathrm{s}$

\section{Subscripts}

in

interior

ext 